\title{
Reducing the incidence of infection after caesarean section: implications of prophylaxis with antibiotics for hospital resources
}

\author{
Miranda Mugford, John Kingston, Iain Chalmers
}

\begin{abstract}
Objectives-To estimate the cost effectiveness of giving prophylactic antibiotics routinely to reduce the incidence of wound infection after caesarean section.
\end{abstract}

Design-Estimation of cost effectiveness was based, firstly, on a retrospective overview of 58 controlled trials and, secondly, on evidence about costs derived from data and observations of practice.

Setting-Trials included in the overview were from obstetric units in several different countries, including the United Kingdom. The costing study was based on data referring to the John Radcliffe Maternity Hospital, Oxford.

Subjects - A total of 7777 women were included in the 58 controlled trials comparing the effects of giving routine prophylactic antibiotics at caesarean section with either treatment with a placebo or no treatment. Cost estimates were based on data on 486 women who had caesarean sections between January and September 1987.

Main outcome measure-Cost effectiveness of prophylaxis with antibiotics.

Results - The odds of wound infection are likely to be reduced by between about 50 and $70 \%$ by giving antibiotics routinely at caesarean section. Forty one $\mathbf{( 8 . 4 \% )}$ women who had caesarean section were coded by the Oxford obstetric data system as having developed wound infection. The additional average cost of hospital postnatal care for women with wound infection (compared with women who had had caesarean section and no wound infection)

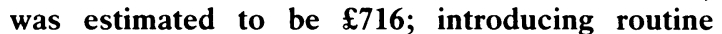
prophylaxis with antibiotics would reduce average costs of postnatal care by between $£ 1300$ and $£ 3900 / 100$ caesarean sections (at 1988 prices), depending on the cost of the antibiotic used and its effectiveness.

Conclusions-The results suggest that giving antibiotics routinely at caesarean section will not only reduce rates of infection after caesarean section but also reduce costs.

National Perinatal

Epidemiology Unit,

Radcliffe Infirmary, Oxford

OX2 6HE

Miranda Mugford, BA,

economist

John Kingston, MSC, research student

Iain Chalmers, FRCOG, director

Correspondence to: Ms Mugford.

BrMed f 1989;299:1003-6

\section{Introduction}

Recovery from caesarean section is more difficult for women who develop postoperative infection. These infections may affect the pelvic organs, the surgical wound, and the respiratory and urinary tracts. Such infections are not uncommon and often not trivial. Moir-Bussy et al estimated that in England and Wales at least $6 \%$ of women who had caesarean section developed wound infection. ${ }^{.}$Their survey found that rates of wound infection in hospitals varied between 0 and $20.5 \%$ and that women with wound infection had a longer stay in hospital. Although they drew attention to the additional costs resulting from infection, they did not do a detailed costing study.

There is strong evidence that the risk of infection after caesarean section can be reduced by prophylactic antibiotics, ${ }^{2}$ yet the only data available that are nationally representative suggest that obstetricians in England and Wales use such prophylaxis rarely. Giving antibiotics for this purpose could add considerably to pharmacy costs, but this might be justifiable not only in terms of averted pain and suffering but also because of cost savings arising from a reduced incidence of infection after caesarean section.

We report the results of a study in which we estimated the costs of care after caesarean section with and without a policy of routine prophylaxis with antibiotics.

\section{Methods}

ASSESSMENT OF EFFECTS OF ROUTINE PROPHYLAXIS WITH ANTIBIOTICS

The effects of routine prophylaxis with antibiotics used at the time of caesarean section were assessed by analysing the results of 58 controlled trials (comprising a total of 7777 women) in which routine treatment with an antibiotic had been compared with either treatment with placebo or no treatment. The methods used in this analysis have been published elsewhere. ${ }^{23}$ Typical estimates of the effects of the policy of prophylaxis were derived by a modification of the Mantel-Haenszel method ${ }^{+}$and expressed as summary odds ratios with their $95 \%$ confidence intervals.

\section{ASSESSMENT OF COSTS}

We used the framework of analysis of cost effectiveness, in which the difference in costs of alternative policies of care was related to the difference in outcome and expressed in terms of cost incurred or saved for each unit of outcome changed. Hospital costs for care of women with and without wound infection after caesarean section were estimated from evidence gathered at the John Radcliffe Maternity Hospital, Oxford, and the Oxford District and Regional Health Authorities. Unless otherwise specified all costs referred to were hospital costs.

We used three main sources of information: observation of ward practice; hospital statistics; and administrative data on costs of different services and resources. Details of the usual postnatal care of women who had had caesarean section, with and without postoperative wound infection, were given by the midwives responsible for the wards concerned at the maternity hospital. Statistics on the length of postnatal stay for women who had delivered at the unit were derived from the Oxford obstetric data system. Overhead costs were taken from the most recently available cost analyses for hospitals in the Oxford 
region. ${ }^{\circ}$ Costs of drugs and laboratory tests were obtained from the pharmacy and microbiology departments of the John Radcliffe Hospital respectively.

\section{DEFINITIONS OF WOUND INFECTION}

We confined our attention to wound infection as the outcome of interest, not because it is the only form of serious infection that has been shown to be reduced by a policy of routine prophylaxis with antibiotics but because previous survey data and current hospital data were more readily available for this outcome than for other serious postoperative infections (for example, endometritis and pelvic abscess). The definition of wound infection used in the overview of trials was not consistent among the different trials included. In the survey conducted by Moir-Bussy et al wound infection was defined as inflammation or sepsis with positive bacterial cultures being obtained from material from the wound.' In our costing study we used the pragmatic definition of wound infection as any mention in the clinical notes of infection of the wound after caesarean section. Breakdown, disruption, and dehiscence of the wound were excluded unless these were accompanied by infection. Mention of wound infection in the clinical notes was usually associated with initiation of treatment with antibiotics.

\section{Results}

EFFECTS OF ROUTINE PROPHYLAXIS WITH ANTIBIOTICS

Table I shows that routine prophylaxis with antibiotics reduced the risk of serious infection after caesarean section. The odds of wound infection, for example, were reduced by between 56 and $72 \%$. Furthermore, although the incidence of postoperative infection was lower after elective than after emergency operations, prophylaxis with antibiotics reduced the incidence similarly in both cases. The reduction in postoperative febrile morbidity was of a similar magnitude whether broad spectrum penicillins or cephalosporins were used. Because there is no evidence from controlled trials that cephalosporins are superior to broad spectrum penicillins in treating patients

TABLE I-Reductions in odds of infection achieved by giving prophylactic antibiotics to women who had caesarean section in 58 controlled trials comprising 7777 women

\begin{tabular}{|c|c|c|c|}
\hline Type of caesarean section & Antibiotic & $\begin{array}{l}\text { Type or outcome of } \\
\text { infection }\end{array}$ & $\begin{array}{c}\text { Odds ratio } \\
\text { (95\% confidence interval) }\end{array}$ \\
\hline \multirow[t]{3}{*}{ Elective or emergency } & Any & Any serious infection & $0.24(0.18$ to 0.32$)$ \\
\hline & & Wound infection & $0.35(0.28$ to 0.44$)$ \\
\hline & & Endometritis & $0.25(0.22$ to 0.29$)$ \\
\hline \multirow{2}{*}{ Elective } & Any & Wound infection & $0.10(0.03$ to 0.36$)$ \\
\hline & & Endometritis & $0.23(0.13$ to 0.42$)$ \\
\hline Elective or emergency & Broad spectrum penicillin & Febrile morbidity & $0.33(0.26$ to 0.42$)$ \\
\hline Elective or emergency & Cephalosporin & Febrile morbidity & $0.31(0.27$ to 0.36$)$ \\
\hline
\end{tabular}

TABLE II - Estimated mean cost (£) of inpatient care at 1986-7 prices for women with and without wound infection after caesarean section

\begin{tabular}{|c|c|c|c|c|c|c|}
\hline \multirow[b]{2}{*}{ Resources } & \multicolumn{2}{|c|}{$\begin{array}{l}\text { Women with } \\
\text { wound infection }\end{array}$} & \multicolumn{2}{|c|}{$\begin{array}{l}\text { Women without } \\
\text { wound infection }\end{array}$} & \multicolumn{2}{|c|}{$\begin{array}{l}\text { Increased cost for women } \\
\text { with wound infection }\end{array}$} \\
\hline & $\begin{array}{l}\text { Each } \\
\text { day }\end{array}$ & $\underset{\text { patient }}{\text { Each }}$ & $\begin{array}{l}\text { Each } \\
\text { day }\end{array}$ & $\underset{\text { patient }}{\text { Each }}$ & $\begin{array}{l}\text { Each } \\
\text { day }\end{array}$ & $\begin{array}{l}\text { Each } \\
\text { patient }\end{array}$ \\
\hline \multicolumn{7}{|l|}{ Staffing: } \\
\hline Medical & 13.97 & $122 \cdot 94$ & $13 \cdot 60$ & $91 \cdot 12$ & $0 \cdot 37$ & $31 \cdot 82$ \\
\hline Midwifery & $90 \cdot 30$ & $794 \cdot 64$ & $37 \cdot 30$ & $249 \cdot 91$ & $53 \cdot 00$ & $544 \cdot 73$ \\
\hline Supplies and equipment & $5 \cdot 07$ & $44 \cdot 62$ & $3 \cdot 39$ & $22 \cdot 71$ & 1.68 & 21.91 \\
\hline Microbiology & 1.43 & $12 \cdot 58$ & 0.75 & 5.03 & 0.68 & 7.55 \\
\hline Pharmacy & 6.82 & $60 \cdot 02$ & $6 \cdot 78$ & $45 \cdot 43$ & 0.04 & $14 \cdot 59$ \\
\hline Other $\ddagger$ & $45 \cdot 44$ & $399 \cdot 87$ & $45 \cdot 44$ & $304 \cdot 45$ & $0 \cdot 00$ & $95 \cdot 42$ \\
\hline Total & 163.03 & $1434 \cdot 66$ & $107 \cdot 26$ & $718 \cdot 64$ & $55 \cdot 77$ & $716 \cdot 02$ \\
\hline
\end{tabular}

*Assuming that mean length of stay was 8.8 days.

A Assuming that mean length of stay was $6 \cdot 7$ days.

$\ddagger$ Includes miscellaneous treatment, haematology, other diagnostic tests, physiotherapy, and other administration, hotel, and overhead costs. with febrile morbidity ${ }^{2}$ we assumed that these two categories of antibiotics had comparable effects.

\section{USE OF RESOURCES FOR POSTNATAL CARE AFTER} CAESAREAN SECTION

The additional costs of postnatal care for women with wound infection after caesarean section arise under five main headings: staffing for daily care; surgical and medical supplies for treatment and wound dressing; laboratory services; drugs; and extended use of a hospital bed with associated overheads for the hospital and hotel costs. We assumed that all other costs for inpatient care did not differ appreciably for women with and without wound infection.

Table II shows the estimated differences in cost each day and for each patient for women with and without infection according to the resources used. Costs each day and for each patient were, respectively, £56 and $£ 716$ higher for women with infection than for those without infection. Most of these differences were accounted for by increased midwifery costs.

Of 486 women who were delivered by caesarean section from January to September 1987, $41(8 \cdot 4 \%)$ were coded in the obstetric data system as having developed wound infection. Women who had had caesarean section had a mean (SD) length of stay of $7 \cdot 0$ $(9 \cdot 3)$ days. For those who developed wound infection the length of stay was $8.8(3.5)$ days; for those without infection or febrile morbidity the length of stay was $6 \cdot 7$ $(7 \cdot 1)$ days $\left(\chi^{2}=7 \cdot 254\right.$ for test of difference between medians, $\left.{ }^{7} \mathrm{df}=1 ; \mathrm{p}<0.005\right)$.

\section{COSTS OF PROPHYLAXIS}

The cost of prophylaxis was calculated as the cost of the drugs required. The evidence from controlled trials suggests that a single dose is less effective than multiple doses, ${ }^{2}$ and we therefore costed a course of three doses. Administration of the drug intravenously in three separate doses given six to eight hours apart during the first 24 hours after delivery would add little to the costs of staff or equipment as women are already cared for quite intensively at this stage. The estimated costs of treating 100 women who had had caesarean section with a broad spectrum penicillin (ampicillin) and a cephalosporin (cefoxitin) were $£ 300$ and $£ 1707$ respectively at 1988 prices.

\section{COST EFFECTIVENESS OF PROPHYLAXIS WITH} ANTIBIOTICS

By applying the costs given in table II the hospital inpatient cost of postnatal care for every 100 women who had had caesarean section, with $8.4 \%$ having developed wound infection, was £77878 (at 1988 prices $)$. This was calculated by the formula: $\operatorname{cost}=(\operatorname{cost}$ per patient without infection $\times 91 \cdot 6)+($ cost per patient with infection $\times 8 \cdot 4$ ).

Table III gives the estimates of the effect on hospital inpatient costs of introducing prophylaxis with antibiotics at caesarean section with various assumptions about effectiveness and about costs. Differences in cost arising from a policy of prophylaxis were estimated separately for the assumptions that the odds of infection would be reduced by either $70 \%$ or $50 \%$ (the approximate limits of the $95 \%$ confidence interval of the typical odds ratio)

With ampicillin for routine prophylaxis and assuming $70 \%$ effectiveness, the average costs of postnatal care would be reduced by $£ 3938 / 100$ caesarean sections. If cefoxitin was used the reduction would be $£ 2532 / 100$ caesarean sections. If prophylaxis reduced the rate of infection by only $50 \%$ the expected reduction in average costs would be $\$ 2707 / 100$ caesarean sections with ampicillin and $£ 1300$ with cefoxitin.

Of the components of the daily inpatient cost of 
TABLE III-Comparison of costs of care after caesarean section at 1987-8 prices with and without prophylaxis with antibiotics according to effectiveness and staff cost

\begin{tabular}{|c|c|c|c|}
\hline Prophylactic antibiotic & $\begin{array}{c}\text { Reduction in } \\
\text { rate of infection }(\%)^{\star}\end{array}$ & $\begin{array}{c}\text { Cost } \\
(£) / 100 \text { caesarean sections } \dagger\end{array}$ & $\begin{array}{l}\text { Estimated change in cost } \\
(\mathfrak{f}) / 100 \text { caesarean section }\end{array}$ \\
\hline \multicolumn{4}{|c|}{ Daily additional cost of midwifery $=£ 53 \ddagger$} \\
\hline $\begin{array}{l}\text { None } \\
\text { Ampicillin }\end{array}$ & $\begin{array}{l}50 \\
70\end{array}$ & $\begin{array}{ll}77 & 878 \\
75 & 171 \\
73 & 940\end{array}$ & $\begin{array}{l}-2707 \\
-3938\end{array}$ \\
\hline Cefoxitin \{ & $\begin{array}{l}50 \\
70\end{array}$ & $\begin{array}{l}76578 \\
75346\end{array}$ & $\begin{array}{l}-1300 \\
-2532\end{array}$ \\
\hline \multicolumn{4}{|c|}{ Daily additional cost of midwifery $=£ 7.85 \ddagger$} \\
\hline $\begin{array}{l}\text { None } \\
\text { Ampicillin }\end{array}$ & $\begin{array}{l}50 \\
70\end{array}$ & $\begin{array}{l}74541 \\
73502 \\
72946\end{array}$ & $\begin{array}{l}-1039 \\
-1595\end{array}$ \\
\hline Cefoxitin \{ & $\begin{array}{l}50 \\
70\end{array}$ & $\begin{array}{l}74909 \\
74353\end{array}$ & $\begin{array}{l}+368 \\
-188\end{array}$ \\
\hline
\end{tabular}

$\star$ Assuming rate of infection without prophylaxis $=8 \cdot 4 \%$

†Calculated as: (expected number with infection $\times$ cost per patient with infection $)+($ expected number withou infection $\times$ cost per patient without infection).

$\ddagger$ For women with wound infection.

postnatal care that differ for women with and without infection, midwifery staffing was the most important. Our estimates of the differences in cost brought about by a policy of prophylaxis may be larger than they would be elsewhere because at the John Radcliffe Hospital an isolation ward (with variable rates of occupancy) is used for treating women with wound infection after caesarean section. Table III therefore also gives estimates of the differences in cost assuming that the overall daily cost of midwifery for women with wound infection is reduced from $£ 90.30$ to $£ 45.15$ that is, reducing the difference in daily costs of midwifery from $£ 53$ to $£ 7.85$. Under this assumption a reduction in cost would still be achieved by giving ampicillin prophylactically, even if it reduced the odds of serious infection by only $50 \%$. In this case costs of postnatal care would be reduced by $£ 1039 / 100$ caesarean sections. With cefoxitin, if the odds of wound infection were reduced by $70 \%$ the saving would be $£ 188 / 100$ caesarean sections. If cefoxitin reduced the odds of infection by only $50 \%$ the cost associated with a policy of prophylaxis would be $£ 88$ for each case of wound infection that was averted.

\section{Discussion}

Important scope for preventing infection after caesarean section lies, firstly, in reducing the number of unnecessary caesarean sections ${ }^{8}$ and secondly, in considering factors that reduce the risk of infection after an operation. These factors include those that apply to operations in general, such as minimising the duration of hospital admission before an operation; delaying shaving the site of the operation until immediately before the operation; sterilising swabs and instruments, the hands of the members of the operating team, the patient's skin, and the air in the operating theatre ${ }^{9}$; and paying attention to good surgical technique ${ }^{10}$ and minimising the duration of the operation. " Other factors that are specific to caesarean section and may be important include minimising the number of vaginal examinations after rupture of the membranes and making a transverse rather than a vertical skin incision."

Our calculations suggest that a policy of routine prophylaxis with antibiotics is not only effective in reducing the incidence of infection in women after caesarean section but also likely to reduce average hospital costs. Indeed, we probably underestimated the savings because we considered only the prevention of wound infection and not the prevention of other serious infections that are reduced by a policy of routine prophylaxis with antibiotics. Furthermore, we concentrated on costs of hospital postnatal care: women also receive postnatal care from their general practitioners, from community midwives, and (especially those who have had caesarean sections) at follow up hospital clinics. We did not have data on differential use of these resources by women with and without infection. Family costs are also likely to be higher when a woman has infection, both because she is in hospital longer and because she will probably need more support at home. ${ }^{12}$

There are some objections to a policy of prophylaxis. Firstly, the incidence of side effects of antibiotics in women or their babies might be considered to outweigh their advantages. A full course of ampicillin causes a rash in about $5 \%$ of people and sometimes causes diarrhoea. It might also lead to an increase in oral thrush in infants who are breast fed. Furthermore, short courses of prophylaxis with antibiotics may suppress infection during the hospital admission but abscesses may develop at the site of stitches after discharge home. It seems reasonable to assume that side effects are less common with three dose courses of antibiotics than with longer courses. A single dose of antibiotics for prophylaxis, although likely to be less effective than multiple doses, ${ }^{2}$ could be expected to be associated with an even lower incidence of side effects and would reduce the cost of the policy.

Any increase in the amount of antibiotics used increases the risk that resistant strains of bacteria will emerge..$^{1314}$ Depending on the background risk of infection and the dose of the antibiotic, however, the use of antibiotics for prophylaxis can reduce the total load of antibiotics in a maternity unit. In the present study, assuring a three dose course of prophylactic antibiotics in a unit with a background risk of infection of $8.4 \%$ and a $50 \%$ reduction in the risk of infection, the total number of days of treatment with antibiotic would be increased by between 60 and $115 \%$, depending on the length of the course of treatment. A unit with a background risk of infection over $16 \%$ would experience a reduction in the use of antibiotics if a prophylactic policy of giving three doses was introduced. Routine use of a single dose for prophylaxis would result in a reduction in the total amount of antibiotics used in units with rates of infection of between 16 and $8 \%$.

The possible limitations of our methods for estimating hospital costs must also be considered. A more refined study might have based costings on detailed observations of care or analysis of case notes, or both. Such research would itself be expensive and time consuming. The ideal would be if, in the design of sufficiently large randomised trials to compare the effectiveness of two policies, differences in resources used by each policy could also be measured. ${ }^{15}$ This method was used in a comparison of two different prophylactic antibiotics with a placebo in women having hysterectomy. ${ }^{16}$ The study showed that including data about use of resources can alter conclusions about which policy to adopt.

Lastly, the hospital on which we based our cost estimates was possibly atypical. The daily costs of inpatient care were not the highest or the lowest among similar hospitals in the same regional health authority. ${ }^{6}$ Indeed, costs of midwifery staffing for each inpatient day were comparatively low, and as staffing was a major component of the differences in cost observed even greater differences might be found in other hospitals. The degree to which reductions in average costs can be realised in practice will also depend on local arrangements for providing care after caesarean section.

There is no evidence that a policy of routine prophylaxis with antibiotics at caesarean section results in harmful effects that outweigh its benefits. Our results suggest that as well as reducing serious postoperative infection and the associated unpleasant symptoms such a policy also results in reduced hospital 
costs. In Britain, where obstetricians seem to be conservative in their use of antibiotics for prophylaxis compared with doctors in North America and Australia, there is scope for extending the use of prophylactic antibiotics, even if they are adopted routinely only for women at increased risk of developing infection. ${ }^{117}$ Possible adverse ecological effects of increasing the total antibiotic load within hospitals should be investigated by randomisation of hospitals rather than individual women to routine antibiotic prophylaxis.

We thank our colleagues Murray and Eleanor Enkin, who did most of the analysis of the relevant controlled trials, and staff at the John Radcliffe Maternity Hospital, the Oxfordshire Health Authority, and the Oxford Regional Health Authority, who helped us in many ways. In particular we thank Dr C Redman and Mrs P Yudkin for providing access to data from the Oxford obstetric data system and the midwifery staff, who helped us learn about their work. We thank Philippa Claiden for typing the manuscript and our colleagues at this unit and the John Radcliffe Maternity Hospital, particularly Dr Richard Mayon-White for his helpful comments. The paper is based on research done by JK as a project for an MSc in health economics at the University of York. MM and IC are funded by the Department of Health. 1 Moir-Bussy BR, Hutton RM, Thompson JR. Wound infection after
caesarean section. F Hosp Infect 1984;5:359-70.

2 Enkin M. Enkin E, Chalmers I, Hemminki I. Antibiotics and caesarean section. In: Chalmers I, Enkin M, Keirse MJNC, eds. Effective care in pregnancy and childhirth. Oxford: Oxford University Press, 1989:1246-69.

3 Chalmers I, Hetherington J, Elbourne D, Keirse MJNC, Enkin M. Materials and methods used in synthesizing evidence to evaluate the effects of care during pregnancy and childbirth. In: Chalmers I, Enkin $M, K$ eirse MJNC, eds. Effective care in pregnancy and childhirth. Oxford: Oxford University Press, 1989:39-65.

+ Yusuf S, Peto R, Lewis J, Collins R, Sleight P. Beta-blockade during and after myocardial infarction: an overview of the randomised controlled trials. Prog Cardiovasc Dis 1985;27:336-71.

5 Drummond MF. Stoddart GL, Torrance GM. Methods for the economic evaluation of health care programmes. Oxford: Oxford Medical Publications, 1987:5-17.

6 Oxford Regional Health Authority. Summary of cost statements 1986-1987. Oxford: Oxford Regional Health Authority, 1987.

7 Siegel S. Non-parametric statistics for the behavioral sciences. Tokyo: McGraw Hill, 1956.

8 Lomas J, Enkin M. Variations in operative delivery rates. In: Chalmers I, Enkin M, Keirse MJNC. eds. Effective care in pregnancy and childbirth. Enkin M, Keirse MJNC. eds. Effective care in
Oxford: Oxford University Press, 1989:1182-95.

9 Pollock AV. Surgical prophylaxis: the emerging picture. Lancet 1988; $1: 225-30$. 10 Pearson JF, Rees G. Technique of caesarean section. In: Chalmers I, Enkin M, Keirse MJNC, eds. Effective care in pregnancy and childhirth. Oxford: Oxford University Press, 1989:1234-45.

11 Webster J. Post-caesarean wound infection: a review of the risk factors. Aust NZ F Obstel Gynaecol 1988;28:201-7.

12 National Childbirth Trust. Postnatal infection. London: National Childbirth Trust, 1988.

13 Tullus K, Busman LG. Ecological impact of ampicillin and cefuroxime in neonatal units. Lancet 1989;i:1405-7.

14 Mead PB. Prophylactic antibiotics and antibiotic resistance. Semin Perinatol 1977;1:101-11.

15 Mugford M, Drummond MF. The role of economics in the evaluation of care In: Chalmers I, Enkin $M$, Keirse MJNC, eds. Effective care in pregnancy and In: Chalmers 1, Enkin $M$, Keirse $M J N C$, eds. Effective car in
childhirth. Oxford: Oxford University Press, 1989:86-98.

16 Davey PG, Duncan ID, Edward D, Scott AC. Cost-benefit analysis of cephranidine and mezlocillin prophylaxis for abdominal and vaginal hysterectomy. Br f Obstet Gynaecol 1988;95:1170-7.

17 Pelle $\mathrm{H}$, Jepsen OB, Larsen SO, et al. Wound infection after caesarean section Infect Control 1986;7:456-61.

Accepted 2 August 1989

\section{Early mobilisation and outcome in acute sprains of the neck}

\section{A McKinney}

\section{Abstract}

Objective-To assess the long term effect of early mobilisation exercises in patients with acute sprains of the neck after road accidents.

Design-Single blind randomised prospective study of patients receiving physiotherapy, advice on mobilisation, or on an initial period of rest followed up after two years by postal questionnaire.

Setting-Accident and emergency department in urban hospital.

Patients -247 Consecutive patients (mean age at injury 30.6 years) presenting within 48 hours after injury with no pre-existing disease of the neck or serious skeletal injury. Of these, 167 patients responded to the questionnaire; 77 who responded but had not completed their treatment or review course were included in the analysis as a fourth group (non-attenders)

Main outcome measure-Presence of symptoms after two years.

Results-Of the 167 patients $(68 \%)$ responding,

Accident and Emergency

Department, Royal

Victoria Hospital, Belfast

BT12 6BJ, Northern

Ireland

L A McKinney, FRCS, senior

registrar

Correspondence to: Accident and Emergency

Department, Ulster

Hospital, Dundonald,

Belfast BT16 0RH,

Northern Ireland.

BrMed F 1989;299:1006-8. the percentage of patients still with symptoms was not significantly different in those receiving rest or physiotherapy $(46 \%, 12 / 26 v 44 \%, 24 / 54)$, but that in those receiving advice on early mobilisation was significantly lower $(23 \%, 11 / 48, p=0.02)$. Of the 104 patients without symptoms, $94(90 \%)$ recovered within six months and $62(60 \%)$ within three months. Patients without symptoms who received advice or physiotherapy wore a collar for a significantly shorter time than those with persistent symptoms (mean duration 1.4 (SD 0.7) months $v 2.8(1.6)$ months, $\mathrm{p}=0.005$ and $1.6(1.1)$ months $v \mathbf{1 . 8}(1.3)$ months, $\mathbf{p}=\mathbf{0 . 0 0 6}$ respectively).

Conclusions-Advice to mobilise in the early phase after neck injury reduces the number of patients with symptoms at two years and is superior to manipulative physiotherapy. Prolonged wearing of a collar is associated with persistence of symptoms.

\section{Introduction}

Management of acute sprain of the neck is a common problem in accident and emergency departments and for those concerned with establishing a prognosis for legal and other purposes. Until recently such management has remained passive, relying on the use of analgesia and rest, usually associated with wearing of collars.' Reviews of patients with acute neck sprain indicates that two years after injury $45-66 \%$ still have symptoms. ${ }^{12}$ Litigation has been considered to be important in the excessive morbidity for this fairly minor soft tissue injury, ${ }^{3}$ but paradoxically in the same report $12 \%$ of patients had serious symptoms and $34 \%$ minor symptoms when interviewed after settlement of litigation. Hohl found that resolution of symptoms was greater in patients for whom litigation was settled early but also found that an appreciable number still had symptoms after litigation had been settled $(62 \%$ with symptoms when settlement occurred 18 months or more after injury). ${ }^{+}$

Early mobilisation improved mobility and reduced pain in acute neck sprains in the early phase,${ }^{6}$ but its long term effectiveness on outcome has not been reported.

I carried out a prospective longitudinal study of 247 patients who had initially been randomised to receive active physiotherapy, advice on mobilisation, or conservative treatment and analysed the outcome two years after injury. Analysis of early outcome had 